\title{
Factors affecting time of spontaneous delivery of dichorionic diamniotic twin pregnancy
}

\author{
Nermeen Mohamed Hefila* \\ Department of Obstetrics and Gynecology, Faculty of Medicine, Alexandria University, El Shatby Medical Campus, \\ Alexandria, Egypt
}

Received: 03 May 2021

Revised: 16 May 2021

Accepted: 18 May 2021

\section{*Correspondence:}

Nermeen Mohamed Hefila,

E-mail: nermeenptsbasem81@gmail.com

Copyright: $\odot$ the author(s), publisher and licensee Medip Academy. This is an open-access article distributed under the terms of the Creative Commons Attribution Non-Commercial License, which permits unrestricted non-commercial use, distribution, and reproduction in any medium, provided the original work is properly cited.

\begin{abstract}
Background: The incidence of twin pregnancy has markedly increased recently due to ART and advanced maternal age. The mother may also experience higher obstetrical morbidity and mortality rates. Aim of the work was to investigate factors affecting the time of spontaneous delivery in dichorionic diamniotic twin pregnancy to improve perinatal outcomes.

Methods: The study was a cross-sectional study had been conducted at Elshatby university maternity hospital between October 2019 to May 2020 on 150 cases of dichorionc diamniotic twins pregnancy admitted for spontaneous delivery. History was taken from all women including general, abdominal and vaginal examination to assess pelvic capacity, first twin presentation, amniotic membrane state and cervical os measurements including cervical dilatation, effacement, station and orientation.

Results: In our study ART twin pregnancies are higher than spontaneous pregnancy regarding the complications. In group $\mathrm{A}$, we found that the uterine contractions are more frequent $(6.5 \mathrm{times} / 30 \mathrm{~min})$ and in $\mathrm{B}$ was $(6.3 \mathrm{times} / 30 \mathrm{~min})$ while in group $\mathrm{C}(2.8$ times $/ 30 \mathrm{~min})(\mathrm{P}<0.001)$. The cervical dilatation in group $\mathrm{A}$ on admission was statistically significant compared with the group B and $\mathrm{C}(\mathrm{p}<0.001)$. PROMs ( $\mathrm{p}=0.042)$ and incompetent internal os of cervix (IIOC, $\mathrm{p}<0.001)$ found to be the most important factor affecting the time of twin delivery specially before 36 weeks.

Conclusions: The frequency and potency of uterine contractions, the cervical internal os dilatation and the state of amniotic membrane are the most important factors affecting the time of delivery in twin pregnancy.
\end{abstract}

Keywords: Twin pregnancy, DCDA twin pregnancy, Onset of labour

\section{INTRODUCTION}

The incidence of twin pregnancy became recently higher than before due to increased rate of ART and advanced maternal age. ${ }^{1}$ Twin fetuses usually result from two separate ova fertilized by two different sperms called dizygotic twins. Less frequently, twins arise from a single fertilized ovum called monozygotic or identical twins. ${ }^{2,3}$

\section{Factors that influence twinning}

Maternal age

The age of the mother at the time of pregnancy is an important risk factor for multiple births. Dizygotic twinning frequency is four times increased between 15-37 years. $^{4}$ 


\section{Pituitary gonadotropin}

Increased rate of stimulating multiple follicles occur at this age group 15-37 years old. ${ }^{5}$ But now with ART, the incidence of twining is increased in advanced maternal age.

Parity

Increasing parity shows to independently increase the incidence of twinning in all populations studied. ${ }^{6}$

\section{Heredity}

A determinant of twinning, the family history specially of the mother that is more important than that of the father. ${ }^{7}$ The age, fertility to multifetal gestation, weight and race are important genetic factors. ${ }^{8}$

Also, the incidence of twin pregnancy is increased in the first month after stopping the COCS due to increased amount of FSH and LH released in the first spontaneous cycle after stopping the COCS. ${ }^{9,10}$

\section{Infertility therapy}

Ovulation induction with FSH plus chorionic gonadotropin or clomiphene citrate remarkably enhances the likelihood of multiple ovulations. The infertility therapy including ovarian stimulation followed by proper timing intercourse or IUI. ${ }^{10}$

\section{Pregnancy complications}

\section{Spontaneous abortion}

ART twin pregnancy are at increased risk for abortion compared with spontaneous pregnancy. ${ }^{11}$

\section{Low birth weight}

Birth weights in twin infants closely paralleled those of singletons until 28 to 30 weeks gestation. Thereafter, twin birth weights progressively lagged. At 35 to 36 weeks and thereafter, twin birth weights clearly differ from singleton one. ${ }^{12-14}$

In discordant dizygotic pregnancies, difference in placental perfusion between both fetuses is responsible for the discordancy which also may associated with fetal congenital anomalies, genetic syndromes and infection. ${ }^{13,14}$

\section{Hypertension}

Data suggest that fetal number and placental mass are involved in preeclampsia pathogenesis. Women with twin pregnancies have double levels of antiangiogenic soluble fms-like tyrosine kinase-1 (sFlt-1) than singletons due to larger placental mass not placental pathology. ${ }^{15,16}$

\section{Preterm birth}

Delivery before term is a major reason for high neonatal mortality and morbidity in multifetal pregnancy. Prematurity is increased sixfold and tenfold in twins and triplets, respectively in their review. ${ }^{17}$

Similar to singleton pregnancies, approximately 60 percent of preterm births in twins are indicated, about a third result from spontaneous labor and 10 percent follow prematurely ruptured membranes. ${ }^{18}$

Preterm labor is common in multifetal pregnancies and may complicate up to 50 percent of twin, 75 percent of triplet and 90 percent of quadruplet pregnancies. ${ }^{19}$

Although the causes of preterm delivery in twins and singletons may be different, neonatal outcome is generally the same at similar gestational ages except for the discordant twin as the cause of dicordancy may has long lasting effect. ${ }^{20}$

\section{Prolonged pregnancy}

Twin neonates delivered at 40 weeks or beyond had the same features of post term singletons. ${ }^{21}$

\section{Fetal demise}

Single fetal death during late second and early third trimester presents the greatest risk to the surviving twin. Although the risks of subsequent death or neurological damage to the survivor are comparatively increased for monochorionic twins at this gestational age, the risk of preterm delivery is equally increased in mono and dichorionic twins. ${ }^{22}$

Regardless, unless there is a hostile intrauterine environment, the goal should be to prolong pregnancy. Time of delivery electively after conservative management of a late second or early third trimester single fetal death is an issue of debate. Dichorionic twins can probably be safely delivered at term. Monochorionic twin gestations are more difficult to manage and are often delivered between 34 and 37 weeks gestation. ${ }^{23}$

Investigators found that cervical canal length (affacement) and fetal fibronectin concentration in the cervix were predictive of preterm birth. At 24 weeks, a cervical canal length of $\leq 25 \mathrm{~mm}$ is a major factor for prediction of preterm delivery before 32 weeks. At 28 weeks, an elevated fetal fibronectin level was the best factor indicating preterm labour. 


\section{Prevention of preterm birth}

\section{Intramuscular progesterone therapy}

Although somewhat effective in reducing recurrent preterm delivery in pregnant with a singleton pregnancy, weekly injections of $17 \alpha$-hydroxyprogesterone caproate (17-OHPC) are not effective for multifetal gestations. ${ }^{23}$

\section{Vaginal progesterone therapy}

Micronized progesterone administered vaginally to women with twins is of uncertain benefit but some studies show that $100 \mathrm{mg}$ of micronized progesterone intravaginally daily between 24 to 34 weeks reduces rates of delivery before 37 weeks.

\section{Cervical cerclage}

Prophylactic cerclage has no or little effect in improvement of perinatal outcome in women with multifetal pregnancies. Studies have included women who were not specially selected and those who were selected because of a shortened cervix that was identified sonographically. ${ }^{24-26}$

\section{Pessary}

A vaginal pessary that encircles and theoretically compresses the cervix, alters the inclination of the cervical canal, and relieves direct pressure on the cervical internal os has been proposed as an alternative to cerclage.

\section{Aim}

Aim of the study was to investigate factors affecting the time of spontaneous delivery in dichorionic diamniotic twin pregnancy in order to improve perinatal outcomes according to main determinant factor.

\section{METHODS}

Cross-sectional study of 150 pregnant eligible twin pregnancies attending at Elshatby university maternity hospital between October 2019 till May 2020 and all those babies delivered. Maternal and perinatal data had been obtained from mothers and medical files to find the correlation between time of dichorionic diamniotic twin delivery and neonatal complications. Total cases had been divided into three groups according to the gestational age they delivered in. Group (A) less than 32 weeks gestation, group (B) between 32 and 35+6 weeks gestation, group (C) and over 36 weeks gestation.

\section{Exclusion criteria}

Monochorionic twins pregnancy, fetal conditions that might need caesarean section, maternal conditions that might need caesarean section, presence of false labor pain, cases of severe discordant growth and both twin IUFD were excluded from the study.

\section{Detailed and careful history was taken from all women}

Personal history included name, age, occupation, residence and special habits of medical importance.

Obstetric history including last menstrual period, gestational age and regular antenatal care were taken.

Past history including any medical disorder like diabetes mellitus, hypertension or any surgical procedure were taken.

History of present pregnancy such as duration of pregnancy from last menstrual period, spontaneous or induction of pregnancy, any complications occurred or any medication used during pregnancy were noted.

\section{Examination of the patient}

\section{General examination}

General examination as regards to level of consciousness, vital data and complexion were done.

\section{Abdominal examination}

Abdominal examination as regards to fundal level, lie of the fetus, true labour uterine contractions diagnosis and monitoring the fetal heart rate were done.

\section{Pelvic examination}

Pelvic examination as regards to pelvic capacity, first twin presentation, state of amniotic membrane and cervical assessment as regard cervical dilatation, effacement and orientation were done.

\section{Investigations}

$\mathrm{CBC}, \mathrm{RH}$, trans-abdominal ultrasound, trans-vaginal ultrasound and CTG. All women will be had vaginal examination for assessment of their pelvis. All women will be had trans-abdominalltrans-vaginal ultrasound for assessment of twins' condition. All women will be tested by intrapartum fetal heart monitoring CTG. TVUS was done to identify any abnormal findings as placenta previa or absence of fetal heart motion and presence of cervical mucus sludge. Also, to assess the cervical canal length and internal os diameter.

\section{Ethical approval}

This study was approved ethically by ethics committee for the scientific research. All institutional and national guidelines for the care and use of animals (insects) were followed. 


\section{Statistical analysis}

Data were collected and analyzed using IBM SPSS software package version 20.0 (Armonk, NY: IBM Corp).

\section{RESULTS}

We reviewed 150 cases of DCDA twin pregnancies delivered at Elshatby university maternity hospital. Among 150 twin deliveries, 23.33\% (35/150) were in group A, 36\% (54/150) in group B and 40.67\% (61/150) in group $\mathrm{C}$. The mean gestational age of admission was 30.8 weeks, 25.4 weeks in group A, 31.8 weeks in group $\mathrm{B}$ and 35.9 weeks in group $\mathrm{C}$.

The mean maternal age was 24.83 years. Preterm birth risk was relatively low for women in their late thirties. Risks for adverse outcomes were higher among younger women (Table 1).

Table 1: Comparison between the three studied groups according to demographic data.

\begin{tabular}{|c|c|c|c|c|c|}
\hline Comparison & Group A (N=35) & Group B $(\mathrm{N}=54)$ & Group C ( $\mathbf{N}=61)$ & $\mathbf{F}$ & $\mathbf{P}$ \\
\hline \multicolumn{6}{|l|}{ Age (in years) } \\
\hline Min.-Max. & $18.0-35.0$ & $16.0-39.0$ & $16.0-40.0$ & \multirow{3}{*}{$5.882 *$} & \multirow{3}{*}{$0.003^{*}$} \\
\hline Mean \pm SD. & $26.54 \pm 5.14$ & $24.83 \pm 5.96$ & $28.62 \pm 6.31$ & & \\
\hline Median & 27.0 & 25.0 & 28.0 & & \\
\hline Sig. bet. grps. & \multicolumn{5}{|c|}{$\mathrm{p}_{1}=0.382, \mathrm{p}_{2}=0.227, \mathrm{p}_{3}=0.002^{*}$} \\
\hline
\end{tabular}

F for ANOVA test, pairwise comparison bet. each 2 groups was done using post Hoc test (Tukey); p: p value for comparing between the three groups; $\mathrm{p}_{1}$ : $\mathrm{p}$ value for comparing between group A and group B; $\mathrm{p}_{2}$ : $\mathrm{p}$ value for comparing between group A and group $\mathrm{C}$; $\mathrm{p}_{3}$ : $\mathrm{p}$ value for comparing between group $\mathrm{B}$ and group $\mathrm{C}$; *statistically significant at $\mathrm{p} \leq 0.05$; group $\mathrm{A}$ : less than 32 weeks gestation; group B: between 32 and 35+6 weeks gestation; group C: and over 36 weeks gestation.

Table 2: Comparison between the three studied groups according to obstetric data.

\begin{tabular}{|c|c|c|c|c|c|c|c|c|}
\hline \multirow{2}{*}{ Comparison } & \multicolumn{2}{|c|}{ Group A ( $\mathbf{N}=35)$} & \multicolumn{2}{|c|}{ Group B $(N=54)$} & \multicolumn{2}{|c|}{ Group $C(N=61)$} & \multirow{2}{*}{$\chi^{2}$} & \multirow{2}{*}{$\mathbf{P}$} \\
\hline & Number & $\%$ & Number & $\%$ & Number & $\%$ & & \\
\hline \multicolumn{9}{|l|}{ Pregnancy } \\
\hline Spontaneous & 21 & 60.0 & 31 & 57.4 & 51 & 83.6 & \multirow{2}{*}{$10.732 *$} & \multirow{2}{*}{$0.005^{*}$} \\
\hline ICSI /IUI & 14 & 40.0 & 23 & 42.6 & 10 & 16.4 & & \\
\hline \multicolumn{9}{|l|}{ Parity } \\
\hline Primi & 18 & 51.4 & 26 & 48.1 & 14 & 23.0 & \multirow{2}{*}{$10.803^{*}$} & \multirow{2}{*}{$0.005^{*}$} \\
\hline Multiparty $\geq 1$ & 17 & 48.6 & 28 & 51.9 & 47 & 77.0 & & \\
\hline
\end{tabular}

$\chi^{2}$ : Chi square test; $\mathrm{p}: \mathrm{p}$ value for comparing between the three groups; *statistically significant at $\mathrm{p} \leq 0.05$; group A: less than 32 weeks gestation; group B: between 32 and 35+6 weeks gestation; group C: and over 36 weeks' gestation.

Table 3: Comparison between the three studied groups according to patient complain and finding.

\begin{tabular}{|c|c|c|c|c|c|c|c|c|}
\hline \multirow{2}{*}{ Comparison } & \multicolumn{2}{|c|}{ Group A (N=35) } & \multicolumn{2}{|c|}{ Group B $(\mathbf{N}=54)$} & \multicolumn{2}{|c|}{ Group C $(\mathrm{N}=61)$} & \multirow{2}{*}{$\chi^{2}$} & \multirow{2}{*}{$\mathbf{P}$} \\
\hline & Number & $\%$ & Number & $\%$ & Number & $\%$ & & \\
\hline \multicolumn{9}{|l|}{$\mathrm{C} / \mathrm{O}$} \\
\hline PTLP & 30 & 85.7 & 38 & 70.4 & 6 & 9.8 & $66.166^{*}$ & $<0.001 *$ \\
\hline PROM & 9 & 25.7 & 21 & 38.9 & 11 & 18.0 & $6.333^{*}$ & $0.042 *$ \\
\hline Labour pain & 0 & 0.0 & 2 & 3.7 & 46 & 75.4 & $89.166^{*}$ & $<0.001 *$ \\
\hline $\mathrm{IIOC}^{* *}$ & 8 & 22.9 & 0 & 0.0 & 0 & 0.0 & $20.285^{*}$ & $<0.001 *$ \\
\hline
\end{tabular}

$\chi^{2}$ : Chi square test; $\mathrm{p}$ : $\mathrm{p}$ value for comparing between the three groups; *statistically significant at $\mathrm{p} \leq 0.05 ; * *$ incompetent internal os of cervix; group A: less than 32 weeks gestation; group B: between 32 and 35+6 weeks gestation; group C: and over 36 weeks gestation.

In our study ART twin pregnancy are at higher risk than spontaneous twin pregnancy for adverse maternal and fetal outcomes (Table 2).

We evaluated the parity and a history of preterm labour effect on the outcome of twin gestation and found that the incidence of preterm delivery is higher in nulliparous than multiparous women who had no history of preterm delivery (Table 2).

True labour uterine contractions found more in group A (6.5 times/30 $\mathrm{min}$ ) compared to group B (6.3 times/30 min) 
and group $\mathrm{C}(2.8$ times/30 $\mathrm{min})(\mathrm{p}<0.001)$. The cervical internal os diameter and dilation on admission examination in group A was statistically significant compared with the $\mathrm{B}$ and $\mathrm{C}$ groups $(\mathrm{p}<0.001)$. PROMs $(\mathrm{p}=0.042)$ and incompetent internal os of cervix (IIOC, $\mathrm{p}<0.001)$ represents a strong predictor for preterm labour with gestational age less than 36 weeks of gestation. And all IIOC were found before 32 weeks of gestation on admission. However, pregnancy induced hypertension, gestational diabetes and others did not affect the timing of labour of the twins in this study (Table 3 and 4).
In our study, the incidence of IUGR significantly reduced with increased the gestational age at delivery (Table 5).

In our study, the incidence of NICU admission was significantly higher at group A of gestation. It decreased and disappeared at higher gestational ages. And most common perinatal complication was neonatal respiratory distress syndrome which is highly presented in group A. (Table 6).

Administration of corticosteroids to stimulate fetal lung maturation has been beneficial for twin (Table 6).

Table 4: Comparison between the three studied groups according to medical history.

\begin{tabular}{|c|c|c|c|c|c|c|c|c|}
\hline \multirow{2}{*}{ Comparison } & \multicolumn{2}{|c|}{ Group A (N=35) } & \multicolumn{2}{|c|}{ Group B $(\mathrm{N}=54)$} & \multicolumn{2}{|c|}{ Group C (N=61) } & \multirow[b]{2}{*}{$\chi^{2}$} & \multirow{2}{*}{$\mathbf{P}$} \\
\hline & Number & $\%$ & Number & $\%$ & Number & $\%$ & & \\
\hline \multicolumn{9}{|l|}{ Medical history } \\
\hline No & 26 & 74.3 & 28 & 51.9 & 29 & 47.5 & \multirow{2}{*}{$6.850^{*}$} & \multirow{2}{*}{$0.033^{*}$} \\
\hline Yes & 9 & 25.7 & 26 & 48.1 & 32 & 52.5 & & \\
\hline Anaemic & 7 & 20.0 & 16 & 29.6 & 15 & 24.6 & 1.071 & 0.585 \\
\hline PET & 2 & 5.7 & 10 & 18.5 & 13 & 21.3 & 4.104 & 0.128 \\
\hline GDM & 0 & 0.0 & 3 & 5.6 & 0 & 0.0 & 3.747 & ${ }^{\mathrm{MC}} \mathrm{p}=0.057$ \\
\hline UTI & 0 & 0.0 & 1 & 1.9 & 1 & 1.6 & 0.785 & ${ }^{\mathrm{MC}} \mathrm{p}=1.000$ \\
\hline BA & 0 & 0.0 & 3 & 5.6 & 3 & 4.9 & 1.746 & ${ }^{\mathrm{MC}} \mathrm{p}=0.441$ \\
\hline Cardiac & 0 & 0.0 & 0 & 0.0 & 2 & 3.3 & 1.960 & ${ }^{\mathrm{MC}} \mathrm{p}=0.335$ \\
\hline Hypothyroidism & 0 & 0.0 & 1 & 1.9 & 1 & 1.6 & 0.785 & ${ }^{\mathrm{MC}} \mathrm{p}=1.000$ \\
\hline
\end{tabular}

$\chi^{2}$ : Chi square test; MC: Monte Carlo; $\mathrm{p}$ : $\mathrm{p}$ value for comparing between the three groups; *statistically significant at $\mathrm{p} \leq 0.05$; group A: less than 32 weeks gestation; group B: between 32 and 35+6 weeks gestation; group C: and over 36 weeks gestation.

Table 5: Comparison between the three studied groups according to demographic data of 1st and 2nd fetus.

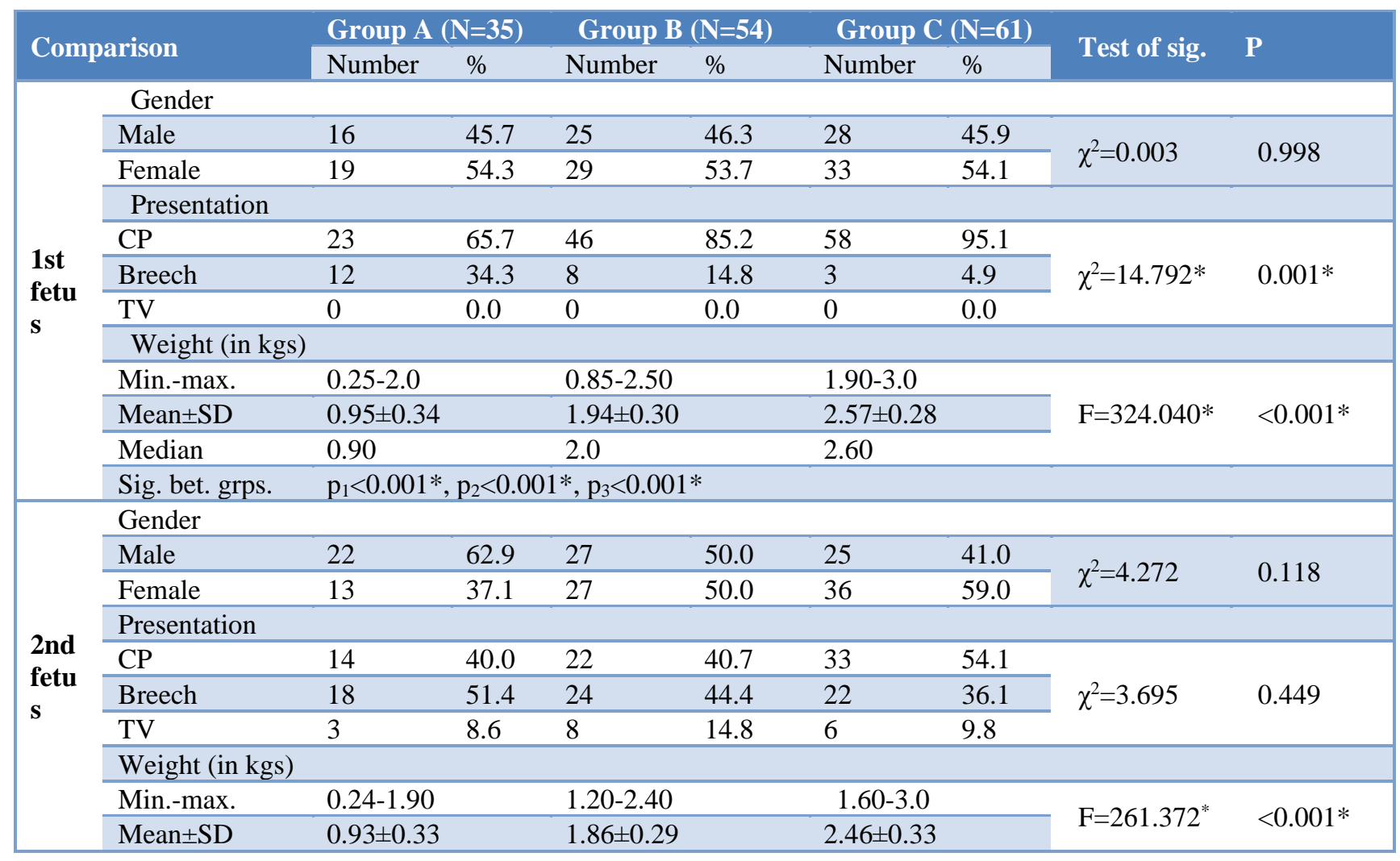




\begin{tabular}{|lllll|l|}
\hline Comparison & Group A $(\mathbf{N}=\mathbf{3 5})$ & \multicolumn{1}{l}{ Group B $(\mathbf{N}=\mathbf{5 4})$} & Group $\mathbf{C}(\mathbf{N}=\mathbf{6 1})$ & \multirow{2}{*}{ Test of sig. $\quad$ P } \\
\hline Median & Number $\%$ & Number $\%$ & Number $\%$ & \\
\hline Sig. bet. grps. & 0.90 & $\mathrm{p}_{1}<0.001^{*}, \mathrm{p}_{2}<0.001^{*}, \mathrm{p}_{3}<0.001^{*}$ & 2.50 & \\
\hline
\end{tabular}

$\chi^{2}$ : Chi square test; F: F for ANOVA test, pairwise comparison bet. each 2 groups was done using post Hoc test (Tukey); p: $p$ value for comparing between the three groups; $\mathrm{p}_{1}: \mathrm{p}$ value for comparing between group $\mathrm{A}$ and group $\mathrm{B} ; \mathrm{p}_{2}$ : $\mathrm{p}$ value for comparing between group A and group C; $\mathrm{p}_{3}$ : $\mathrm{p}$ value for comparing between group B and group $\mathrm{C}$; *statistically significant at $\mathrm{p} \leq 0.05$; group A: less than 32 weeks gestation; group B: between 32 and 35+6 weeks gestation; group C: and over 36 weeks gestation.

Table 6: Comparison between the three studied groups according to NICU admission, completing DEXA and cervical cerculage.

\begin{tabular}{|c|c|c|c|c|c|c|c|c|}
\hline \multirow{2}{*}{ Comparison } & \multicolumn{2}{|c|}{$\begin{array}{l}\text { Group A } \\
(\mathbf{N}=\mathbf{3 5})\end{array}$} & \multicolumn{2}{|c|}{ Group B $(\mathbf{N}=54)$} & \multicolumn{2}{|c|}{ Group C $(\mathrm{N}=61)$} & \multirow{2}{*}{$\chi^{2}$} & \multirow[t]{2}{*}{$\mathbf{P}$} \\
\hline & Number & $\%$ & Number & $\%$ & Number & $\%$ & & \\
\hline \multicolumn{9}{|l|}{ NICU } \\
\hline No & 0 & 0.0 & 45 & 83.3 & 61 & 100.0 & \multirow{2}{*}{$113.819^{*}$} & \multirow{2}{*}{$<0.001 *$} \\
\hline Yes & 35 & 100.0 & 9 & 16.7 & 0 & 0.0 & & \\
\hline \multicolumn{9}{|c|}{ DEXA complete } \\
\hline No & 34 & 97.1 & 34 & 64.2 & 44 & 72.1 & \multirow{2}{*}{$12.802^{*}$} & \multirow{2}{*}{$0.002 *$} \\
\hline Yes & 1 & 2.9 & 19 & 35.8 & 17 & 27.9 & & \\
\hline \multicolumn{9}{|l|}{ Operation } \\
\hline No cerculage & 27 & 77.1 & 40 & 74.1 & 51 & 83.6 & \multirow{2}{*}{1.614} & \multirow{2}{*}{0.446} \\
\hline Cerculage & 8 & 22.9 & 14 & 25.9 & 10 & 16.4 & & \\
\hline
\end{tabular}

$\chi^{2}$ : Chi square test; $\mathrm{p}$ : $\mathrm{p}$ value for comparing between the three groups; *statistically significant at $\mathrm{p} \leq 0.05$; group A: less than 32 weeks gestation; group B: between 32 and 35+6 weeks gestation; group C: and over 36 weeks gestation.

\section{DISCUSSION}

Adverse pregnancy outcomes are more common in twin pregnancy than singleton gestation, predominantly due to increased risks for preterm delivery. The perinatal morbidity and mortality are markedly decreased in twin pregnancy due to improvement of neonatal facilities and modalities of mangment. ${ }^{27}$ So the ideal time of twin delivery is at 38 weeks or beyond to minimize adverse neonatal outcomes unless there is maternal indication of preterm termination. ${ }^{28}$

This study revealed that in twin pregnancies there is a high risk of preterm delivery that is about $85 \%, 70.4 \%$ and $9.8 \%$ for birth A, B and C group respectively. In about $80 \%$ of cases of preterm delivery, this is the consequence of spontaneous labor or PPROM. The results showed that in twin pregnancies cervical canal length is more important than obstetrical history of preterm delivery as a predictor for preterm labour.

Pakrashi et al found in their results of study of almost 300,000 live births that the incidence of preterm labour associated with PROM increased with gestational plurality from 13 percent with singletons to 20 percent with triplets or more. ${ }^{29}$

Preterm labor is common in multifetal pregnancies and may complicate up to 50 percent of twin, 75 percent of triplet and 90 percent of quadruplet pregnancies. ${ }^{30}$
In an analysis of nearly 350,000 twin births, Kogan and coworkers found that in 16 year period of studying and collecting data ends in 1997, the term birth rate among twins decreased by 22 percent. ${ }^{31}$

Joseph et al attributed this decline to an increased rate of indicated preterm deliveries. This trend is not necessarily negative as it was associated with decreased adverse perinatal outcomes among twins that reached 34 weeks. ${ }^{32}$

Results gathered from 300,000 twin births, Kahn et al found that at and above 39 weeks, the rate of stillbirth is very high. At Parkland hospital, twin gestations is considered to be prolonged at 40 weeks of gestation. ${ }^{33}$

McMahon et al found that women with twin gestations at 24 weeks with negative fibrinoectin and closed cervix on digital examination and no cervical internal os changes on ultrasonic examination had low risk of preterm labour before 32 weeks. $^{34}$

In a systematic review and meta-analysis of trans-vaginal cervical length for anticipating preterm birth, CondeAgudelo et al concluded that cervical canal length between 20-24 weeks of gestation is a major indicator factor for spontenous preterm labour in twin asymptomatic pregnant females. These authors found that a cervical length $\leq 20$ $\mathrm{mm}$ was most accurate for predicting birth $<34$ weeks, with a specificity of 97 percent and positive likelihood ratio of $9.0 .^{35}$ 
Aina-Mumuney et al reviewed 1035 deliveries results showed that the twin pregnancy in primigravida pregnant women delivered one week earlier than multipapous pregnant women of the same condition. ${ }^{36}$

The present study results that the incidence of preterm labour was found higher in ART twin pregnancy than spontaneous twin conception and these results are in accordance with those reported by Moise et al and Tallo et al who performed studies of 40 and 68 IVF twins pregnancy, respectively. ${ }^{37}$ These investigators found that the adverse neonatal outcomes regarding prematurity, low birth weight and high morbidity and mortality were higher in ART twin gestation than spontaneous twin pregnancy. ${ }^{38}$ Similarly, Bernasko et al also found that high incidence of discordancy among the ART twin and adverse pregnancy outcome in comparison to spontenous twin pregnancy. ${ }^{39}$ Olivennes et al study showed that after 28 weeks the perinatal outcomes are the same in ART twin pregnancy and spontenous twin pregnancy. ${ }^{40}$

Our study findings go along with the findings of Friedman et al who found that in the twins less than 36 weeks, there is no accelated fetal maturation in comparison to singleton pregnancy. ${ }^{40}$ The studies of Luke et al and Kiely et al found that the incidence of IUGR is higher in twin pregnancy 38 weeks of gestation. In our study, the incidence of IUGR significantly reduced as the gestational age is more advancing at time of delivery.

In this study, the most important factors affecting the time of labour in twins were the true uterine contractions frequency and potency, condition of amniotic membrane and condition of cervical internal os and cervical canal. Other distributing factors for onset of labour are maternal age, parity, pregnancy (spontaneous or induction) and maternal medical condition.

\section{Study limitations}

Cases withdrawal due to non-available places at NICU or incubators was the only obstacle of this study.

\section{CONCLUSION}

In conclusion, we found out that the most important clinical factors affecting the timing of delivery in twins are the true uterine contraction frequency and potency, state of amniotic membrane and cervical dilatation and effacement. Other distributing factors for onset of labour are maternal age, parity, pregnancy (spontaneous or induction) and maternal medical history among maternal complications. The statistical results showed that the role of these clinical factors was more significant in the group with early gestational age. An appropriate use of tocolytics could help improving perinatal outcomes in twin pregnancies. Therefore, physicians should regard these factors during examinations and effectively use tocolytic agents to increase the gestational age toward full term to reduce perinatal complications.
Funding: No funding sources

Conflict of interest: None declared

Ethical approval: The study was approved by the Institutional Ethics Committee

\section{REFERENCES}

1. Russell RB, Petrini JR, Damus K, Mattison DR, Schwarz RH. The changing epidemiology of multiple births in the United States. Obstet Gynecol. 2003;101(1):129-35.

2. Sadler TW. Longman Medical Embryology. 10th ed. United States: Philadelphia: Lippincott Williams and Wilkins; 2006: 104-8.

3. Gambon HM. Essential of obstetrics and gynecology. 4th ed. Saunders; 2006: 183-5.

4. Abel EL, Kruger ML. Maternal and paternal age and twinning in the United States, 2004-2008. J Perinat Med. 2012;40(3):237-9.

5. White $\mathrm{C}$, Wyshak G. Inheritance in human dizygotic twinning. N Engl J Med. 1964;271:1003-5.

6. McClamrock HD, Jones HW, Adashi EY. Ovarian stimulation and intrauterine insemination at the quarter centennial: implications for the multiple births epidemic. Fertil Steril. 2012;97(4):802-9.

7. Lee YM, Wylie BJ, Simpson LL, D'Alton ME. Twin chorionicity and the risk of stillbirth. Obstet Gynecol. 2008;111:301-8.

8. Barbara LH, Robyn H, Scott R. Williams wards Obstetrics. 24th ed. United States: New York: McGraw-Hill Education; 2014.

9. Odibo AO, Cahill AG, Goetzinger KR, Harper LM, Tuuli MG, Macones GA. Customized growth charts for twin gestations to optimize identification of smallfor-gestational age fetuses at risk of intrauterine fetal death. Ultrasound Obstet Gynecol. 2013;41(6):63742.

10. Benirschke K, Kim CK. Multiple pregnancy.1. N Engl J Med. 1973;288(24):1276-84.

11. Dey M, Saraswat M. Outcomes of Multifetal Reduction: A Hospital-Based Study. J Obstet Gynaecol India. 2018; 68(4):264-9.

12. Kogan MD, Alexander GR, Kotelchuck M, MacDorman MF, Buekens P, Martin JA, et al. Trends in twin birth outcomes and prenatal care utilization in the United States, 1981-1997. JAMA. 2000;284(3):335-41.

13. Schieve LA, Tatham L, Peterson HB, Toner J, Jeng G. Spontaneous abortion among pregnancies conceived using assisted reproductive technology in the United States. Obstet Gynecol. 2003; 101(5 Pt 1):959-67.

14. Ray B, Platt MP. Mortality of twin and singleton livebirths under 30 weeks' gestation: a populationbased study. Arch Dis Child Fetal Neonatal Ed. 2009;94(2):140-3.

15. Goldenberg RL, Iams JD, Miodovnik M, Dorsten JPV, Thurnau G, Bottoms S, et al. The preterm prediction study: risk factors in twin gestations. Am J Obstet Gynecol. 1996;175:1047-53. 
16. Durnwald CP, Momirova V, Rouse DJ, Caritis SN, Peaceman AM, Sciscione A, et al. Second trimester cervical length and risk of preterm birth in women with twin gestations treated with $17-\alpha$ hydroxyprogesterone caproate. J Matern Fetal Neonatal Med. 2010;23(12):1360-4.

17. Caritis SN, Rouse DJ, Peaceman AM, Sciscione A, Momirova V, Spong CY, et al. Prevention of preterm birth in triplets using 17alpha-hydroxyprogesterone caproate: a randomized controlled trial. Obstet Gynecol. 2009;113:285-92.

18. Combs CA, Garite T, Maurel K, Das A, Porto M, Obstetrix Collaborative Research Network. 17Hydroxyprogesterone caproate for twin pregnancy: a double-blind, randomized clinical trial. Am J Obstet Gynecol. 2011;204(3):221.

19. Elimian A, Figueroa R, Nigam S, Verma U, Tejani N, Kirshenbaum N. Perinatal outcome of triplet gestation: does prophylactic cerclage make a difference? J Matern Fetal Neonatal Med. 1999;8(3):119-22.

20. Liem S, Schuit E, Hegerman M, Bais J, deBoer K, Bloemenkamp $\mathrm{K}$, et al. Cervical pessaries for prevention of preterm birth in women with a multiple pregnancy (ProTWIN): a multicenter, open-label randomised controlled trial. Lancet. 2013;382(9901):1341-9.

21. Smith GSC, Fleming KM, White IR. Birth order of twins and risk of perinatal death related to delivery in England, Northern Ireland, and Wales, 1994- 2003: retrospective cohort study. BMJ. 2007;334(7593):576

22. D'Alton ME. Delivery of the second twin. Obstet Gynecol. 2010;115(2):221.

23. Fox NS, Rebarber A, Dunham SM, Saltzman DH. Outcomes of multiple gestations with advanced maternal age. J Matern Fetal Neonatal Med. 2009;22(7):593-6.

24. Prapas N, Kalogiannidis I, Prapas I, Xiromeritis P, Karagiannidis A, Makedos G. Twin gestation in older women: antepartum, intrapartum complications, and perinatal outcomes. Arch Gynecol Obstet. 2006;273(5):293-7.

25. Kristensen S, Salihu HM, Keith LG, Kirby RS, Pass MA, Fowler KB. Impact of advanced maternal age on neonatal survival of twin small-for-gestational-age subtypes. J Obstet Gynaecol Res. 2007;33(3):259-65.

26. Blickstein I, Goldman RD, Mazkereth R. Incidence and birth weight characteristics of twins born to mothers aged 40 years or more compared with 35-39 years old mothers: a population study. J Perinatal Med. 2001;29(2):128-32.

27. Luke B, Brown MB. Contemporary risks of maternal morbidity and adverse outcomes with increasing maternal age and parity. Fertil Steril. 2007;88(2):28393.
28. Blickstein I, Goldman RD, Mazkereth R. Maternal age and birth weight characteristics of twins born to nulliparous mothers: a population study. Twin Res. 2001;4(1):1-3.

29. Pakrashi T, Defranco EA. The relative proportion of preterm births complicated by premature rupture of membranes in multifetal gestations: a populationbased study. Am J Perinatol. 2013;30(1):69-74.

30. Arabin B, Halbesma JR, Vork F, Hübener M, vanEyck $\mathrm{J}$. Is treatment with vaginal pessaries an option in patients with a sonographically detected short cervix? J Perinat Med. 2003;31(2):122-33.

31. Roberts D, Dalziel S. Antenatal corticosteroids for accelerating fetal lung maturation for women at risk of preterm birth. Cochrane Database Syst Rev. 2006;3:004454.

32. Joseph KS, Allen AC, Dodds L, Vincer MJ, Armson BA. Causes and consequences of recent increases in preterm birth among twins. Obstet Gynecol. 2001;98(1):57-64.

33. Kahn B, Lumey LH, Zybert PA, Lorenz JM, ClearyGoldman J, D'Alton ME, et al. Prospective risk of fetal death in singleton, twin, and triplet gestations: implications for practice. Obstet Gynecol. 2003;102(4):685-92.

34. McMahon KS, Neerhof MG, Haney EI, Thomas HA, Silver RK, Peaceman AM. Prematurity in multiple gestations: identification of patients who are at low risk. Am J Obstet Gynecol. 2002;186(6):1137-41.

35. Conde-Agudelo A, Romero R, Hassan SS, Yeo L. Transvaginal sonographic cervical length for the prediction of spontaneous preterm birth in twin pregnancies: a systematic review and metaanalysis. Am J Obstet Gynecol. 2010;203(2):128.

36. Aina-Mumuney AJ, Rai KK, Taylor MY, Weitz CM, Chisholm CA. Nulliparity and duration of pregnancy in multiple gestation. Obstet Gynecol. 2004;104(1):110-3

37. Tallo CP, Vohr B, Oh W, Rubin LP, Seifer DB, Haning RV. Maternal and neonatal morbidity associated with in vitro fertilization. J Pediatr. 1995; 127(5):794-800

38. Moise J, Laor A, Armon Y, Gur I, Gale R. The outcome of twin pregnancies after IVF. Hum Reprod. 1998;13(6):1702-5.

39. Bernasko J, Lynch L, Lapinski R, Berkowitz RL. Twin pregnancies conceived by assisted reproductive techniques: maternal and neonatal outcomes. Obstet Gynecol. 1997;89(3):368-72.

40. Olivennes F, Kadhel P, Rufat P, Fanchin R, Fernandez $\mathrm{H}$, Frydman R. Perinatal outcome of twin pregnancies obtained after in vitro fertilization: comparison with twin pregnancies obtained spontaneously or after ovarian stimulation. Fertil Steril. 1996;66(1):105-9.

Cite this article as: Hefila NM. Factors affecting time of spontaneous delivery of dichorionic diamniotic twin pregnancy. Int J Reprod Contracept Obstet Gynecol 2021;10:2961-8. 